Pacific Journal of Mathematics

ON THE ACTION OF A LOCALLY COMPACT GROUP ON $E_{n}$ 


\title{
ON THE ACTION OF A LOCALLY COMPACT GROUP ON $E_{n}$
}

\author{
F. J. HAHN
}

It is known [2, p. 208] that if a locally compact group acts effectively and differentiably on $E_{n}$ then it is a Lie group. The object of this note is to show that if the differentiability requirements are replaced by some weaker restrictions, given later on, the theorem is still true. Let $G$ be a locally compact group acting on $E_{n}$ and let the coordinate functions of the action be given by $f_{i}\left(g, x_{1}, \cdots, x_{n}\right), 1 \leqq i \leqq n$. For economy we introduce the following notation

$$
Q_{i j}(g, t, x)=\frac{f_{i}\left(g, x_{1}, \cdots, x_{j}+t, \cdots, x_{n}\right)-f_{i}\left(g, x_{1}, \cdots, x_{j}, \cdots, x_{n}\right)}{t} .
$$

We denote by $\sigma\left(Q_{i j}(e, 0, x)\right)$ the oscillation of $Q_{i j}(g, t, x)$ at the point $(e, 0, x)$.

Before proceeding there is one simple remark to be made on matrices. If $A=\left(a_{i j}\right)$ is an $n \times n$ matrix such that $\left|a_{i j}-\delta_{i j}\right|<(1 / n)$ then $A$ is non-singular. If $A$ were singular there would be a vector $x$ such that $\sum_{i} x_{i}^{2}=1$ and $A x=0$. From the Schwarz inequality it follows that $x_{i}^{2}=\left(\sum_{j}\left(a_{i j}-\delta_{i j}\right) x_{j}\right)^{2}<(1 / n)$ and consequently $1=\sum x_{i}^{2}<1$ which is impossible. If $\left|a_{i j}-\delta_{i j}\right| \leqq(\alpha / n)$, where $0<\alpha<1$, then the determinant of $A$ is bounded away from zero since the determinant is a continuous function and the set $\left\{a_{i j}:\left|\alpha_{i j}-\delta_{i j}\right| \leqq(\alpha / n)\right\}$ is compact in $E_{n^{2}}$.

TheOREm 1. If $T$ is a pointwise periodic homeomorphism of $E_{n}$ then $T$ is periodic.

$$
\text { Proof. [2, p. 224.] }
$$

THEOREM 2. If $G$ is a compact, zero dimensional, monothetic group acting effectively on $E_{n}$ and satisfying

$$
\sigma\left(Q_{i j}(e, 0, x)\right)<\frac{\varepsilon}{n}, \quad 0<\varepsilon<1, \text { for each } x \text { in } E_{n} ;
$$

then $G$ is a finite cyclic group.

Proof. Since $G$ is monothetic, let $a$ be an element whose powers are dense in $G$. It is enough to show that there is a power of $a$ which leaves $E_{n}$ pointwise fixed since the action of $G$ is effective.

Received April 12, 1960. The author is a National Science Foundation Fellow. 
If $q$ is a positive integer we let

$$
T_{i}^{q}(g, x)=x_{i}+f_{i}(g, x)+\cdots+f_{i}\left(g^{q-1}, x\right) .
$$

If $y=\left(y_{i}\right)$ and $x=\left(x_{i}\right)$ let

$$
T_{i j}^{q}(g, x, y)=\frac{T_{i}^{q}\left(g, x_{1}, \cdots, x_{j-1}, y_{j}, \cdots, y_{n}\right)-T_{i}^{q}\left(g, x_{1}, \cdots, x_{j}, y_{j+1}, \cdots, y_{n}\right)}{y_{j}-x_{j}}
$$

for $y_{j} \neq x_{j}$ and zero otherwise. If we let $y=f(g, x)$ then we obtain

$$
\begin{aligned}
f_{i}\left(g^{q}, x\right)-x_{i} & =T_{i}^{q}(g, y)-T_{i}^{q}(g, x) \\
& =\sum_{j=1}^{n} T_{i j}^{q}(g, x, y)\left(y_{j}-x_{j}\right) \\
& =q \cdot \sum_{i=1}^{n} \frac{1}{q} T_{i j}^{q}(g, x, y)\left(y_{j}-x_{j}\right) .
\end{aligned}
$$

Because of the fact that $f_{i}(e, x)=x_{i}$ and because of $(*)$ it follows that there is a compact neighborhood $U(x)$ of the identity of $G$ such that if $g, \cdots, g^{q} \in U(x)$ then $\left|(1 / q) T_{i j}^{q}(g, x, y)-\delta_{i j}\right| \leqq(\alpha / n), 0<\varepsilon<\alpha<1$. It follows that if $T$ is the matrix with entries $(1 / q) T_{i j}^{q}(g, x, y)$ then $T$ is non-singular and its determinant is bounded away from zero uniformly in $q$, so the determinant of the inverse is bounded uniformly in $q$; thus

$$
(f(g, x)-x)=(y-x)=\left(\delta_{i j} \frac{1}{q}\right) \cdot T^{-1} \cdot\left(f\left(g^{q}, x\right)-x\right) .
$$

Since $G$ is monothetic and zero dimensional there is a power of $a$ such that if $g=a^{p}$ then all the powers of $g$ lie in $U(x)$. Since $U(x)$ is compact it follows that the vectors $f\left(g^{q}, x\right)-x$ are bounded uniformly in $q$ and thus $f(g, x)-x=f\left(a^{p}, x\right)-x=0$. Hence $a$ is pointwise periodic on $E_{n}$ and it follows from Theorem 1 that it is periodic and consequently has a power leaving $E_{n}$ pointwise fixed.

From this it follows quickly that if $G$ is a locally compact group acting effectively on $E_{n}$ and satisfying $(*)$ then it is a Lie group. This follows from the fact that since $G$ is effective it must be finite dimensional [1] and then if $G$ is not a Lie group it must contain a compact, non-finite zero dimensional subgroup $H$ [2, p. 237] which acts effectively. $H$ has small subgroups which act effectively and it follows from Newman's theorem $[3,4]$ that $H$ cannot have arbitrarily small elements of finite order. Thus $H$ has an element $a$ of infinite order such that the compact subgroup generated by $a$ acts effectively on $E_{n}$ and satisfies (*) but by Theorem 2 this is impossible.

\section{BIBLIOGRAPHY}

1. D. Montgomery, Finite dimensionality of certain transformation groups, Ill. J. Math. 1, No. 1 (1957), 28-35. 
2. D. Montgomery and L. Zippin, Topological Transformation Groups, Interscience Publishers, New York (1955).

3. M. H. A. Newman, A theorem on periodic transformations of spaces, Quart. J. Math. 2 (1931), 1-8.

4. P. A. Smith, Transformations of finite period, III, Newman's theorem, Ann. of Math. 42 (1941), 446-458.

INSTITUTE FOR AdVANCED STUdY

Princeton, NeW Jersey 



\section{PACIFIC JOURNAL OF MATHEMATICS}

\section{EDITORS}

Ralph S. Phillips

Stanford University

Stanford, California

F. H. BrownelL

University of Washington

Seattle 5 , Washington
A. L. Whiteman

University of Southern California Los Angeles 7. California

L. J. PAIGE

University of California

Los Angeles 24, California

ASSOCIATE EDITORS
E. F. BECKENBACH
D. DERRY
H. L. ROYDEN
E. G. STRAUS
T. M. CHERRY
M. OHTSUKA
E. SPANIER
F. WOLF

\section{SUPPORTING INSTITUTIONS}

UNIVERSITY OF BRITISH COLUMBIA

CALIFORNIA INSTITUTE OF TECHNOLOGY

UNIVERSITY OF CALIFORNIA

MONTANA STATE UNIVERSITY

UNIVERSITY OF NEVADA

NEW MEXICO STATE UNIVERSITY

OREGON STATE COLLEGE

UNIVERSITY OF OREGON

OSAKA UNIVERSITY

UNIVERSITY OF SOUTHERN CALIFORNIA
STANFORD UNIVERSITY

UNIVERSITY OF TOKYO

UNIVERSITY OF UTAH

WASHINGTON STATE COLLEGE,

UNIVERSITY OF WASHINGTON

AMERICAN MATHEMATICAL SOCIETY

CALIFORNIA RESEARCH CORPORATION

HUGHES AIRCRAFT COMPANY

SPACE TECHNOLOGY LABORATORIES

NAVAL ORDNANCE TEST STATION

Printed in Japan by International Academic Printing Co., Ltd., Tokyo, Japan

Reprinted 1966 in the United States of America 


\section{Pacific Journal of Mathematics}

\section{Vol. 11, No. $1 \quad$ November, 1961}

A. A. Albert, Generalized twisted fields ............................ 1

Richard Arens, Operational calculus of linear relations ................... 9

John Herbert Barrett, Disconjugacy of a self-adjoint differential equation of the fourth order ....................................... 25

Paul Richard Beesack, Hardy's inequality and its extensions ............... 39

Julius Rubin Blum and David Lee Hanson, On invariant probability measures.

II .............................................

Robert Allen Bonic, Symmetry in group algebras of discrete groups.......... 73

R. Creighton Buck, Multiplication operators ...................... 95

Jack Gary Ceder, Some generalizations of metric spaces ................. 105

Meyer Dwass, Random crossings of cumulative distribution functions ......... 127

Albert Edrei, Wolfgang H. J. Fuchs and Simon Hellerstein, Radial distribution and

deficiencies of the values of a meromorphic function ............... 135

William Cassidy Fox, Harmonic functions with arbitrary local singularities ..... 153

Theodore Thomas Frankel, Manifolds with positive curvature ............... 165

Avner Friedman, A strong maximum principle for weakly subparabolic

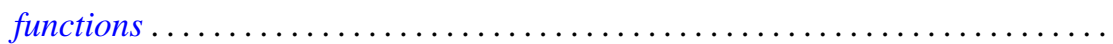

Watson Bryan Fulks and J. O. Sather, Asymptotics. II. Laplace's method for

multiple integrals ......................................

Adriano Mario Garsia and Eugene Richard Rodemich, An embedding of Riemann

surfaces of genus one ..................................... 193

Irving Leonard Glicksberg, Weak compactness and separate continuity......... 205

Branko Grünbaum, On a conjecture of H. Hadwiger .................. 215

Frank J. Hahn, On the action of a locally compact group on $E_{n} \ldots \ldots \ldots \ldots \ldots . . \ldots 221$

Magnus R. Hestenes, Relative hermitian matrices ..................... 225

G. K. Kalisch, On similarity invariants of certain operators in $L_{p} \ldots \ldots \ldots \ldots .247$

Yitzhak Katznelson and Walter Rudin, The Stone-Weierstrass property in Banach

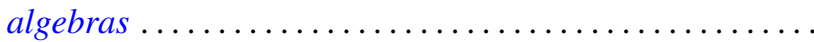

Samir A. Khabbaz, The subgroups of a divisible group $G$ which can be represented as intersections of divisible subgroups of $G \ldots \ldots \ldots \ldots \ldots \ldots \ldots \ldots \ldots . \ldots \ldots 7$

Marvin Isadore Knopp, Construction of a class of modular functions and forms .......................................... 275

Charles Alan McCarthy, Commuting Boolean algebras of projections .......... 295

T. M. MacRobert, Transformations of series of E-functions ................ 309

Heinz Renggli, An inequality for logarithmic capacities ................. 313

M. S. Robertson, Applications of the subordination principle to univalent functions .......................................... 315

David Sachs, Partition and modulated lattices ..................... 325

Frank S. Scalora, Abstract martingale convergence theorems ............... 347

Elbert A. Walker, Torsion endomorphic images of mixed Abelian groups ........ 375

Morgan Ward, The prime divisors of Fibonacci numbers................. 379

Charles R. B. Wright, On the nilpotency class of a group of exponent four....... 387 